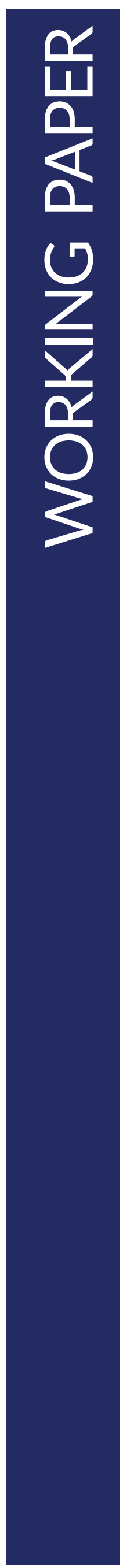

\title{
Covid-19: Thinking Differently about Education Research Impact
}

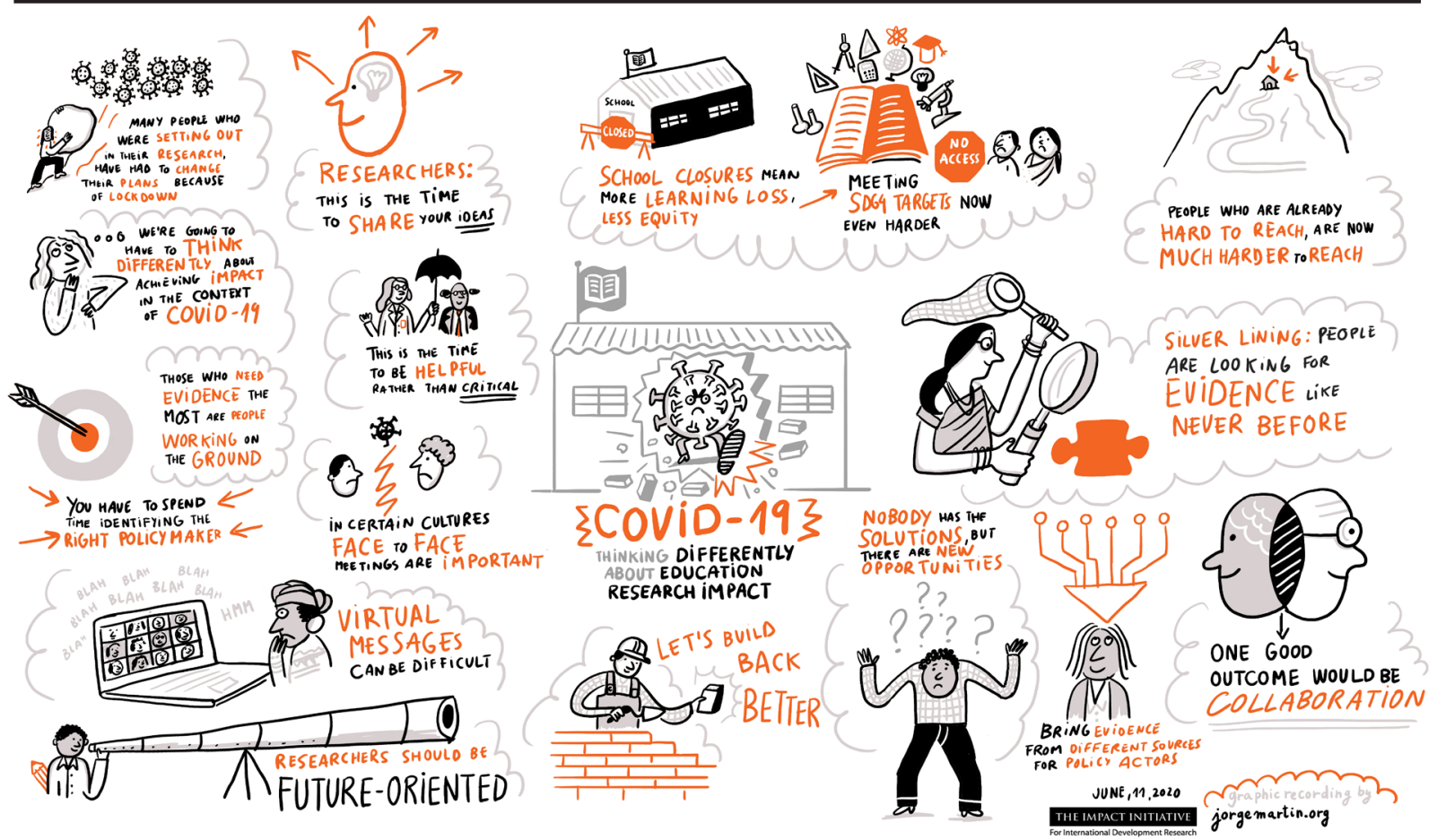

Figure 1: Visualisation of the online discussion focusing on Covid-19 and education research impact. Image: (CJorge Martin 2020

\section{THE IMPACT INITIATIVE PROGRAMME}

The Impact Initiative programme, funded by the UK's Economic and Social Research Council (ESRC) and the former UK Department for International Development which merged with the Foreign \& Commonwealth Office on 2 September 2020 to become the Foreign, Commonwealth $\&$ Development Office (FCDO), aims to increase the uptake and impact of research from two research programmes jointly funded by ESRC-FCDO: the Joint Fund for Poverty Alleviation Research and the Raising Learning Outcomes in Education Systems Research Programme. The Initiative achieves this through a process of identifying synergies between the programmes and grant holders, and supporting them collectively and individually to exploit influencing and engagement opportunities. As well as facilitating knowledge exchange and policy engagement on behalf of the two programmes, the Initiative develops programme-level research communication outputs in order to ensure each programme's research is effectively communicated and shared.

\section{BACKGROUND}

The effects of Covid-19 have been far reaching. Beyond being a recognised global health emergency, it has wide-ranging effects on children's schooling around the world. As a result of school closures, 1.2 billion $^{1}$ learners are estimated to be out of school, ${ }^{2}$ with expectations that the most vulnerable children in poorer countries around the world may not return. A further 258 million children and youth were already out of school. ${ }^{3}$ The reliance on education technology and parental support to home learning is often not a feasible alternative to many of these children, meaning that they will face 
a significant loss in learning from an already extremely low base. UNESCO estimates that around 250 million children were not able to achieve the basics in literacy even before the pandemic. ${ }^{4}$

Since 2014, researchers funded by the Economic and Social Research Council (ESRC) and the Foreign, Commonwealth $\&$ Development Office (FCDO) under the Raising Learning Outcomes (RLO) in Education Systems Research Programme have been undertaking research to understand the reasons behind the global learning crisis that existed before the pandemic, and to propose evidence-based solutions. Covid-19 makes such research even more imperative. However, along with its other disruptions, the pandemic also undermines conventional pathways adopted by researchers to achieve impact. Being able to achieve specific changes in policy and practice through new evidence will undoubtedly be affected by the pandemic. Researchers, donors, policymakers, and practitioners all face challenges to their work as a result of the effects of the pandemic on the education sector including not being able to meet face to face due to travel restrictions to a reallocation of programme funds.

This paper draws on lessons from a webinar organised by the Impact Initiative that explored how researchers need to think differently about impact for education policy and practice in the context of Covid-19. It provides insights from education policy actors and researchers on how they are adapting their thinking on the types of impact that can be achieved in the context of Covid-19 and includes quotes from some of the speakers at the event.

\section{CHALLENGES FOR EDUCATION}

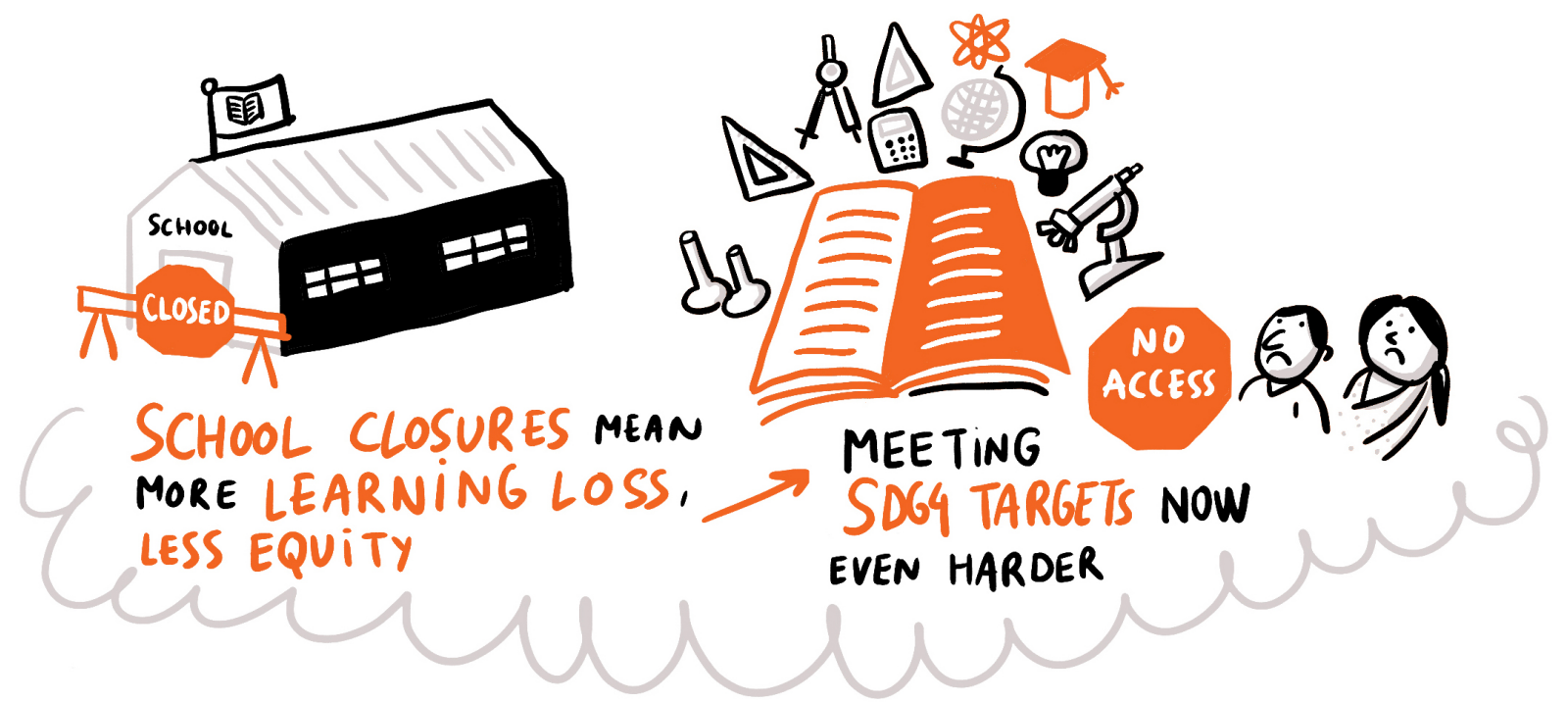

At the start of the global Covid-19 pandemic, there were obvious, immediate effects on health systems around the world. However, all aspects of daily life have been disrupted in some way - with short- and long-term effects on social interactions, finances, wellbeing, and education.

UNESCO ${ }^{5}$ quickly pulled together a database on education disruption and response, which was updated daily. Overall, an average of 91 per cent (1.6 billion) of students were affected by school closures across 191 countries from the middle of March to the end of May, in addition to the 258 million children who were already out of school.

'People who are vulnerable are now even harder to reach.'

Nompumelelo Mohohlwane, Deputy Director: Research, Monitoring and Evaluation, Department of Basic Education, South Africa
Many organisations rushed to develop resources to inform the global debate on the immediate impacts of the pandemic on education, and how to keep learning going. As school closures have persisted, longer-term effects are apparent, such as how to catch up on learning losses, which inevitably affect students from more disadvantaged socioeconomic groups more gravely. Covid-19 is reversing decades of progress towards the Sustainable Development Goals (SDGs): the effects have devastated the most vulnerable and left them further behind. As such, important questions arise about how to address widening inequality gaps, both by ensuring the most disadvantaged children can return to school and how adaptations can be made to enable them to compensate for their lost learning.

All of these challenges need to be supported by strong evidence. However, education researchers are now tasked with the need to adapt their plans for achieving specific changes in policy and practice and consider what needs to be done differently so that translating evidence into policy and practice can be managed and adapted within the context of the pandemic. 
There is great uncertainty about future research, and this includes practical challenges in undertaking research during a pandemic. For example, research may be affected by school closures meaning that data collection within schools is no longer feasible; in response, some researchers are adapting their work by using phone surveys or are basing analysis on pre-existing data that can be used to respond to relevant questions in the context of the pandemic.

Given the re-orientation of research, the ability to achieve different types of impact (see Figure 2) will also undoubtedly be affected. It might, for example, be more difficult for networks and connectivity to be achieved. In parallel timely availability of evidence could result in conceptual and instrumental impact, particularly where research findings are collated across different studies in accessible ways.

Three key practical suggestions have emerged from the discussions involving a range of stakeholders which highlight ways in which researchers might try and achieve impact in this context.

\section{New opportunities for building research-policy partnerships}

Research-policy partnerships - long-term, mutually beneficial collaborations - are critical for achieving impact, and they will be even more valuable during the current pandemic. ${ }^{6}$ Researchers who are likely to be of most service in crises might be those who already have trusted relationships with decision makers and key stakeholders.

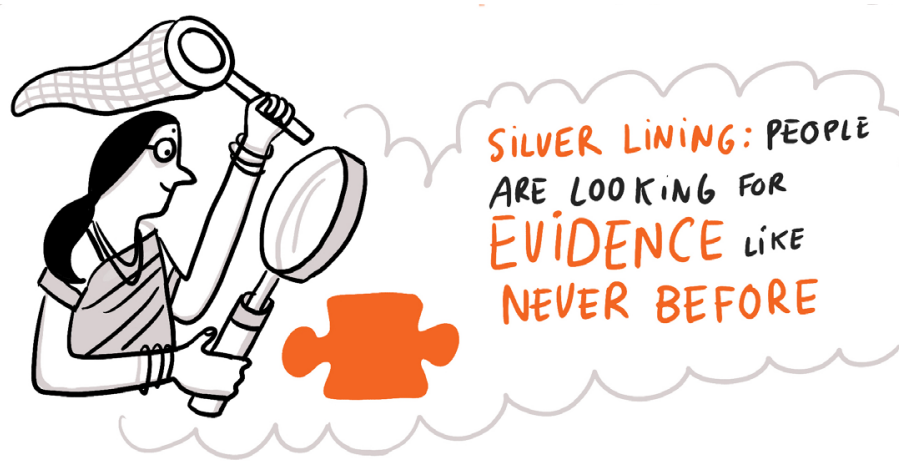

Despite policy work being greatly affected by the restriction of movement and potentially a reallocation of programme funds, policy actors still have an appetite for evidence to inform their response to the effects of the Covid-19 pandemic on education systems. Nompumelelo Mohohlwane, Deputy Director: Research, Monitoring and Evaluation, Department of Basic Education, South Africa said:

[T]his [the pandemic] creates a new opportunity to engage between policymakers and researchers. I think for a lot of researchers, you have been waiting for the moment where [sic.] government can listen to you [sic.]. This is your moment. We are waiting for ideas!

The landscape has created a new opportunity for researchers to engage with policy actors, providing a real opportunity for networks to build messages and to tell a powerful story across a number of different contexts, as highlighted by Laura Savage, Senior Advisor, Education Research Team, DFID:

One of the silver linings of the pandemic is that I have never heard the words 'what's the evidence for this?' said more often... people are looking for data, people are looking for evidence...

One way in which researchers can do this is to engage with busy policy actors, particularly if researchers work together instead of in silos, as they often do. Laura Savage said:

Voices will always be heard louder in a collective. For example, [members of] the 'BETER' [Building EdTech Evidence and Research] Network are coming together to think about how to work together to collect similar data in different countries that tell us a story across different contexts.

Researchers should collaborate, collate information, and work together to re-analyse existing data which might fill in specific data gaps (such as the risk of children being exposed to Covid-19 in formal school settings) or be relevant to specific policy areas - as seen already by the BETER Network which is collecting and inputting data on to a global database to help assess the impact of Covid on education.

As well as launching new studies on the impact of Covid on education, researchers should be synthesising what they know from existing research in order to inform tomorrow's decisions.

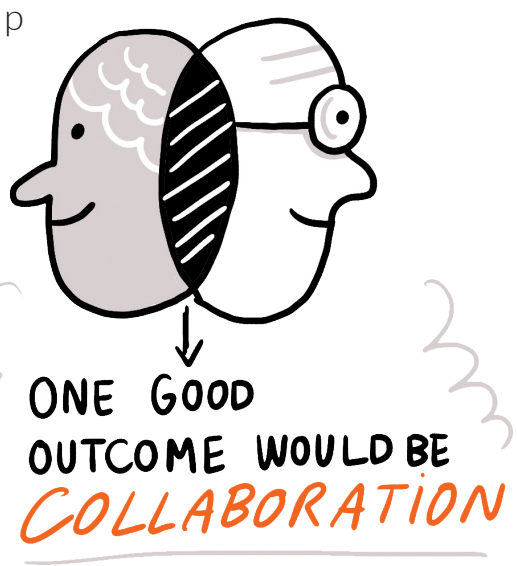

There is also now an opportunity to accelerate a more Southern-led approach (given barriers to international travel) as well as for existing networks and collaborations, including those from across the RLO programme, which encompasses 30 projects focused on 24 countries. Projects span research themes such as teachers and teaching, curriculum and pedagogy, inequality, and school finance and governance. Over the years, these projects have been encouraged to come together to explore new strategies for achieving research impact and to build new networks and links. Facilitated by the Impact Initiative, spaces have been created for researchers to identify synergies and collaborations and these have resulted in successful linking and increased engagement for grant holders with policy organisations. In the current context, the network of researchers provides an opportunity to consider how evidence from the projects could inform planning for 'building back better' as schools re-open, learning from challenges identified in the studies to date.

From a policy-oriented funding perspective, there are hard choices ahead in a post-Covid world in terms of shifting 
priorities with diminished budgets. Researchers need to reflect on how they can work cross-sectorally to answer the questions being asked right now by the global education and health communities. For example, it will be more important than ever for education and health researchers to actively gather evidence to support the safe opening of schools, to include ensuring that hygiene facilities are in place and social distancing measures are appropriate - both from the perspective of children's age and stage of development as well as for their health and safety, and of other workers in schools.

'New spaces for collaboration are opening up because nobody has the solutions to... the challenges that are facing us currently. So we're seeing an openness on the part of many governments to engage with us to figure out solutions together.

Suman Bhattacharjea, Director of Research, ASER Centre, India

Above all, this is the time to strengthen partnerships rather than weaken them because of the challenges of physical distance that have arisen.

\section{Identifying creative approaches to engagement with policy actors}

Real change often involves sustained forms of dialogue but researchers' ability to reach policy actors has been greatly affected by the restriction of movement, as highlighted by Professor Tristan McCowan, University College London:

In certain contexts, face-to-face interactions are particularly important. Not being able to hold the stakeholder meetings as planned has made it difficult.

There is now pressure on researchers to keep relationships going with key in-country stakeholders even if physical meetings are not possible.

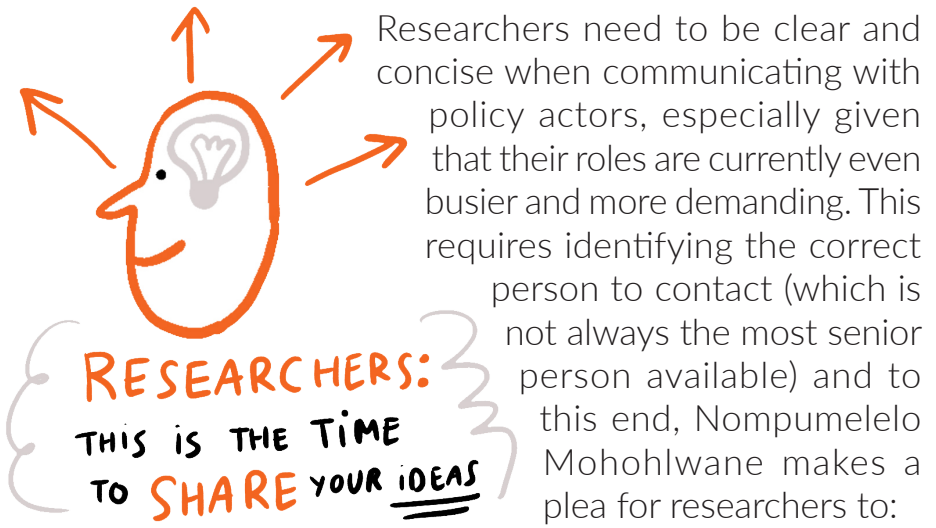

be clear, be concise in your requests and know what you are asking for.... I would encourage you to spend some time in terms of thinking of your network and what information you actually need... [That way] you can identify the right person who is more in the middle of the road rather than right at the top so that your research isn't waiting for a response from the Minister's office.

Researchers should also try engaging via different formats - still keeping messages succinct and accessible. Pandemic challenges mean that researchers should harness the potential of technology such as webinars to connect. Professor Tristan McCowan said:

In terms of the changing of ideas [conceptual impact], we have been forced to be more creative... [regarding] the types of outputs we are doing and different kinds of engagement such as through social media and policy briefs.

\section{Repurposing research to be responsive to current realities}

Researchers should not hesitate to use this unique moment to provide new ideas to feed into policy and action and contribute to the 'building back better' of education systems. Suman Bhattacharjea, Director of Research, ASER Centre, India emphasised that:

... because we don't yet know the magnitude of these impacts [of the pandemic], we will need quick measurements that are able to quickly feed into policy and action on the ground when schools and communities do open up again.

For example, due to the massive expansion in distance learning provision following Covid-19, there is a critical need to understand the effects of this type of learning, particularly which children it is reaching and to what effect.

For example, Pratham in India - a research partner of the RLO project, 'Can Schools' Accountability for Learning be Strengthened from the Grassroots? Investigating the Potential for Community-School Partnerships in India' - was very quick to offer virtual learning opportunities to 11,000 villages across India (providing educational content such as word games and simple sums for parents to do together with their children via messaging services like WhatsApp). According to Pratham's experience, its distance learning programme is proving to be a positive framework for families and communities to engage in ways they had not done pre-Covid. The effects of initiatives of this kind will be valuable to assess in future research, in order to learn lessons for the likely ongoing effects of Covid-19, as well as for future pandemics.

"When we think about "building back better", it is really important to find ways to ensure that this engagement that we know is possible, can continue and thrive even when schools do open and we're back to business as usual.'

Suman Bhattacharjea, Director of Research, ASER Centre, India

Funders can also play a role in allowing for flexible approaches for research to feed into policy at times of crisis such as the Covid-19 pandemic. There are reports of some funders allowing a proportion of their budgets to be relatively undefined. This allows each research partner to be innovative and develop their own approaches to influencing policy in the current situation, depending on context. For example, Professor Tristan McCowan cited participatory action research approaches:

... because of course they know their local needs... it's essential for people to actually participate in that transformative experience for the impact to be able to happen. 
To meet the challenges ahead, the research community will need to restructure its work in relation to policy actors, practitioners, and communities. In particular, researchers will need to build and maintain relationships with decision makers and communities that are focused on collective goals. The ability of diverse communities of researchers and policy actors to find common ground, sustain their interactivity, and adapt to change will have real consequences for the impact of Covid-19 on young learners and their education, with millions of these children and youth already being out of school or years behind in terms of expected learning outcomes.
'For the foreseeable future, we are going to need to adapt to the way we do research - whether it's through phone surveys, social distancing, and learning from each other as we do so... We need to be more the sum of our parts... let's think constructively about what we can do collectively.'

Professor Pauline Rose, Co-Director of the Impact Initiative and Director of the REAL Centre, Faculty of Education, University of Cambridge

\section{COVID-19: THINKING DIFFERENTLY ABOUT EDUCATION RESEARCH IMPACT WEBINAR}

In June 2020, the Impact Initiative convened a discussion with researchers to explore how to think differently about impact for their work in education policy and practice in the context of Covid-19. The event was an opportunity for grant holders from the joint ESRC-FCDO-funded Raising Learning Outcomes (RLO) in Education Systems and Global Challenges Research Fund (GCRF) research programmes to hear from policy actors on how they are adapting their thinking on the types of impact that can be achieved in an education context in these times of Covid-19, and the processes through which researchers can best engage with policy actors in this context. It was an opportunity for grant holders to reflect on what the current context might mean for their plans for achieving impact, and what kind of support is needed.

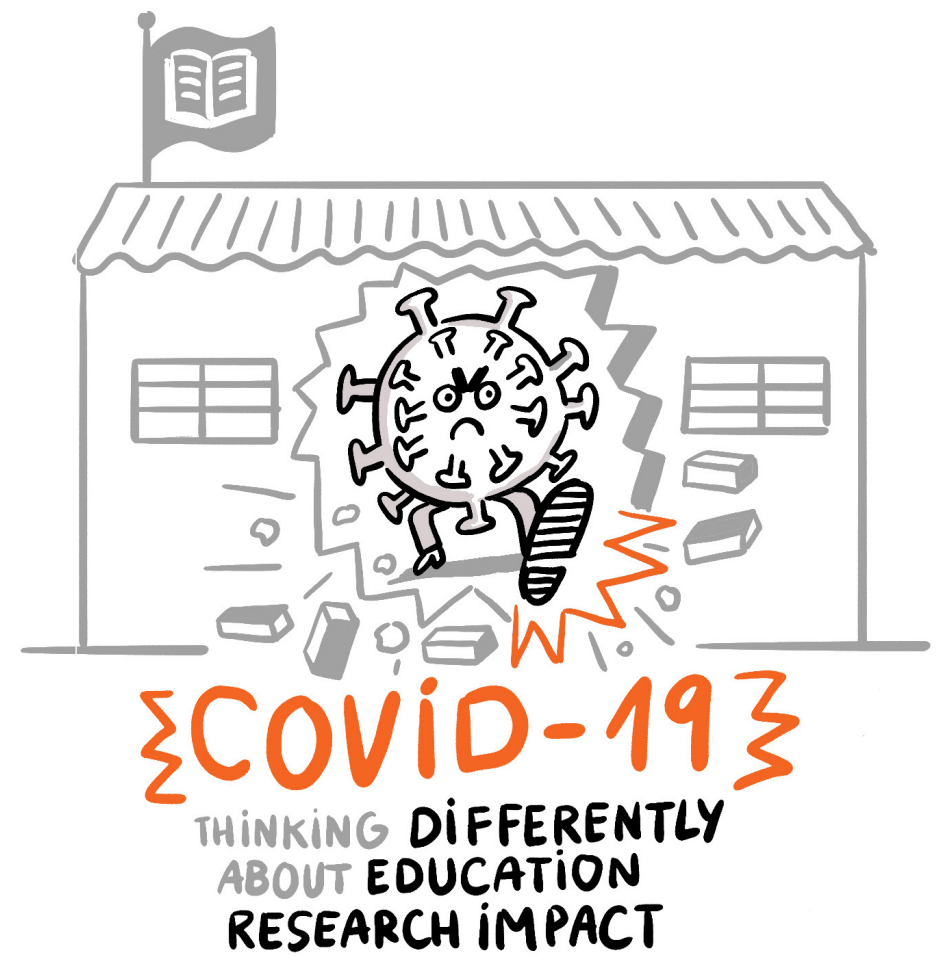

Approximately 80 participants joined the virtual meeting. Professor Pauline Rose, Co-Director of the Impact Initiative and Director of the REAL Centre, University of Cambridge, moderated a panel of four education experts (policymaker, researcher, practitioner, and donor) who shared their thoughts on how translating evidence into policy and practice can be managed and adapted within the context of Covid-19. The panellists were:

- Nompumelelo Mohohlwane, Deputy Director: Research, Monitoring and Evaluation, Department of Basic Education, South Africa;

- Professor Tristan McCowan, University College London;

- Suman Bhattacharjea, Director of Research, ASER Centre, India; and

- Laura Savage, Senior Advisor, Education Research Team, DFID.

Issues that the panellists and grant holders were asked to reflect on included: What will Covid-19 mean for doing research using previously planned methodologies? What will it mean to try and achieve impact in this context, recognising that researchers will have to think very differently? What do we think is appropriate and feasible? What support will be needed going forward, in whatever practical ways that may be?

Grant holders were reminded of the framing of what 'impact' means in the context of their research projects. As defined by the ESRC-DFID Guiding Principles on Uptake, Impact and Communication of Research, projects must have demonstrated impact through at least two of the following four modes (also summarised in Figure 2):

- Instrumental: Seeing a change in policy and practice - for example, how teachers are recruited;

- Conceptual: Changing ways of thinking, raising awareness, and contributions to knowledge - for example, how to think about inclusive education;

- Capacity building: Building capacity of researchers and intermediaries to strengthen research uptake approaches; and

- Networks and connectivity: Building and strengthening networks, connecting up the supply of evidence with the demand for it. 


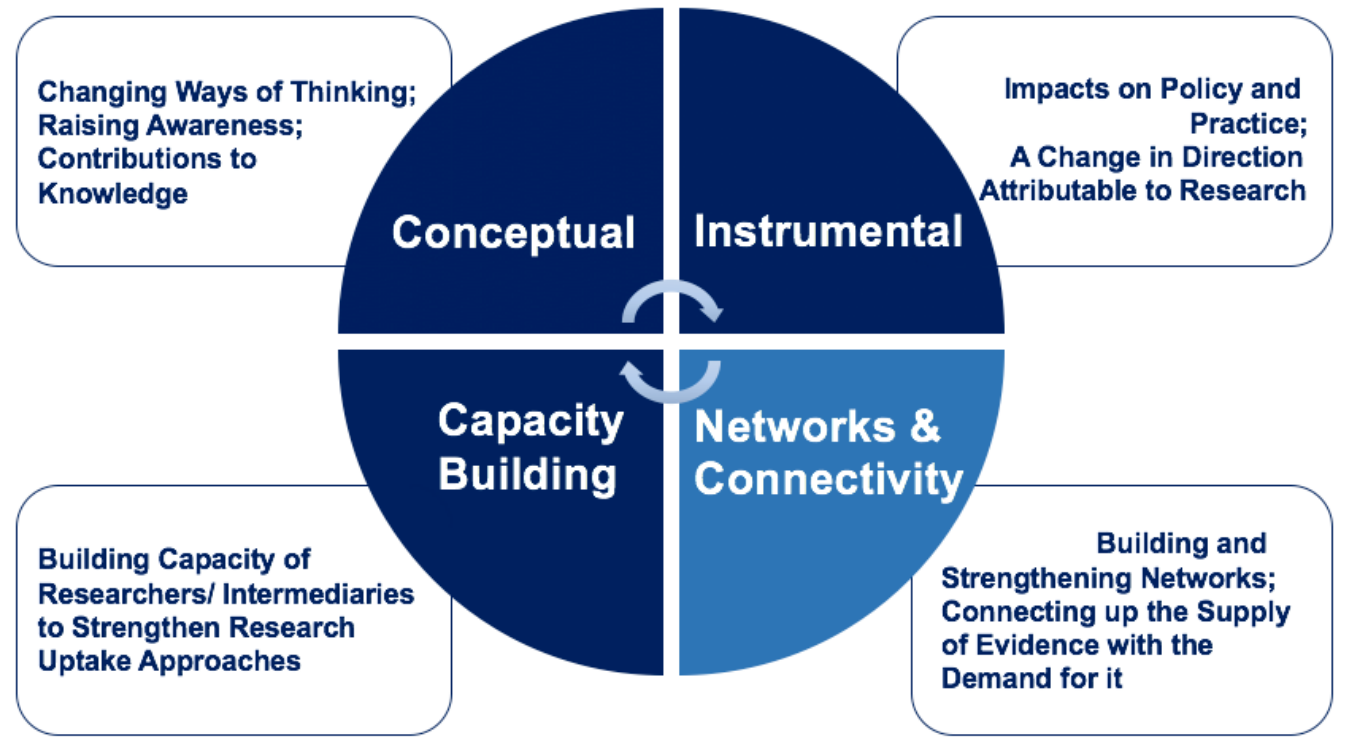

Figure 2: The Impact Initiative 'wheel of impact' based on the ESRC-DFID Guiding Principles on Uptake, Impact and Communication of Research.

Source: Georgalakis and Rose (2019: 2).

Panel presentations were followed by a rich discussion session with grant holders, collectively generating a lot of practical suggestions for how researchers can think differently about education research impact post Covid-19. The key challenges and opportunities from the discussion are summarised in Figure 1, a graphic illustration by Jorge Martin.

\section{Credits}

This Working Paper was written by Professor Pauline Rose, Director, Research for Equitable Access and Learning (REAL) Centre, University of Cambridge and Co-Director of the Impact Initiative; Elizabeth Tofaris, the Impact Initiative Communications Specialist; and Sandra Baxter, Research Uptake Lead, the REAL Centre, University of Cambridge. The direct quotes incorporated in this paper are sourced from the webinar recording and transcription notes and are included with kind permission from the individuals concerned.

\section{Images: ㄷ Jorge Martin 2020}

The Impact Initiative seeks to connect policymakers and practitioners with world-class social science research supported by the ESRC-FCDO Strategic Partnership, maximising the uptake and impact of research from: (i) the Joint Fund for Poverty Alleviation Research, and (ii) the Raising Learning Outcomes in Education Systems Programme. The Impact Initiative endeavours to identify synergies between these programmes and their grant holders, support them to exploit influencing and engagement opportunities, and facilitate mutual learning.

The Impact Initiative is a collaboration between IDS and the University of Cambridge's Research for Equitable Access and Learning (REAL) Centre. This is a product of the Impact Initiative. The material has been funded by the Economic and Social Research Council and UK aid from the UK Government. However, the views expressed do not necessarily reflect the official policies of the UK Government or ESRC

$\longrightarrow$ info@theimpactinitiative.net

@ww.theimpactinitiative.net @The_Impact_Init \#ImpactLessons

All content is available under the Open Government License v.3.0, except where otherwise stated. (c) Institute of Development Studies, 2020 